\title{
THE GROWTH OF BLOCKCHAIN TECHNOLOGY IN INDIA : ITS USES AND POTENTIAL IMPACTS ON ECONOMY
}

\author{
Ms. Shivangi Jaiswal \\ Senior content writer, I Block Technologies Pvt. Ltd, \\ Sector 62, Noida (U.P.)
}

\begin{abstract}
Even though block chain is a young and rapidly evolving technology, it is not too early to assess the opportunities and risks that it presents. The purpose of this paper is to provide a clear-eyed view of the potential of the technology to help meet economic development goals. Throughout the paper, we focus on identifying the questions that development practitioners should be asking technologists, and the challenges that innovators must address for the technology to meet its potential in this space. We also try to simplify some of the more complicated aspects of the technology. Our central finding is that blockchain-based solutions have the potential to increase efficiency and improve outcomes dramatically in some use cases and more marginally in others, however the key constraints to addressing these challenges often remain outside the scope of technology. For blockchain-based solutions to reach their full potential in this space, governments and development organizations first need to take steps that they have often resisted in the past (e.g., donors agreeing to use common reporting systems, governments creating reliable land registry systems). The good news is that excitement about the technology has already generated more interest (and investment) by some of these organizations in addressing these underlying challenges.
\end{abstract}

Keywords- Blockchain, Cryptocurrencies, decentralized ledger.

\section{INTRODUCTION}

Technological innovation is often regarded as the primary driver of long-term economic growth, and the pace of innovation has arguably never been faster. So it is unsurprising that a growing number of development experts have focused their energy on exploring how new digital technologies could be used to reduce poverty and improve the lives of the poor. The idea that innovation can help to not only reduce poverty at low cost but also improve how the public and private sectors function has obvious appeal, particularly in a world where development aid agency budgets are under increasing pressure. Nakamoto et al.(2008) in his work suggested the requirement of an electronic payment system

\author{
Mr. Pankaj Joge \\ Asstt. Professor, Faculty of Management Studies, \\ SSTC, SSGI, Junwani, Bhilai (C.G.)
}

based on cryptographic proof instead of trust, allowing any two willing parties to transact directly with each other without the need for a trusted third party.

Blockchain is one of those emerging new technologies that is slowly but surely taking over the world. It's happening much like the internet, in that, it started in niche communities before it ended up completely dominating the current world economy. As it stands, there are a lot of changes that can be expected in the future courtesy of Blockchain that will affect everything from elections to kilimall offers.

\section{WHAT IS BLOCKCHAIN?}

The blockchain is a peer-to-peer distributed ledger of timestamped transactions. For the purposes of cryptocurrencies, the entire ethos was to decentralize away from central banks through Bitcoin and other cryptocurrencies. Therefore, it's a movement against the centralization and the control of fiat money. While with fiat money, central banks are in control of the ledger, with cryptocurrencies and blockchain technology, the user maintains their own copy of the ledger and all copies of the ledger are synchronized through what is known as a consensus algorithm.

There is so much hype over the blockchain technology now that both private and public sector organizations have opened their eyes and seen the light. Audrey Nesbitt et al.(2018) emphasised on the selection of right blockchain platform for new start-ups. Her work in the field of blockchain technology suggested that there are yet many areas to be discovered which blockchain technology can revolutionise and people currently in the field believe that the adoption of the new technology in business can bring positive transformation. What blockchain technology can offer is not only ever seen before, but will become life-changing for today's generation and be deemed as one of the greatest inventions of modern times.

For the private sector, companies have been exploring the endless possibilities of blockchain for a number of years now, but it's perhaps been over the last 12 months that the noise has begun to crescendo. It's all over the news wires and the recent interest from government agencies has certainly added to the hype. 


\section{International Journal of Engineering Applied Sciences and Technology, 2020 \\ Vol. 4, Issue 9, ISSN No. 2455-2143, Pages 149-152 \\ Published Online January 2020 in IJEAST (http://www.ijeast.com)}

As always, new technologies bring out the statisticians and charts have been doing their rounds, which represent the hype cycle of emerging technologies. One particularly detailed graphic has been produced by Gartner, a leading data and research provider in the Information and Technology space.

The Gartner Hype Cycle illustrates the different phases that an emerging technology passes through before it becomes a part of everyday life.

Figure inserted

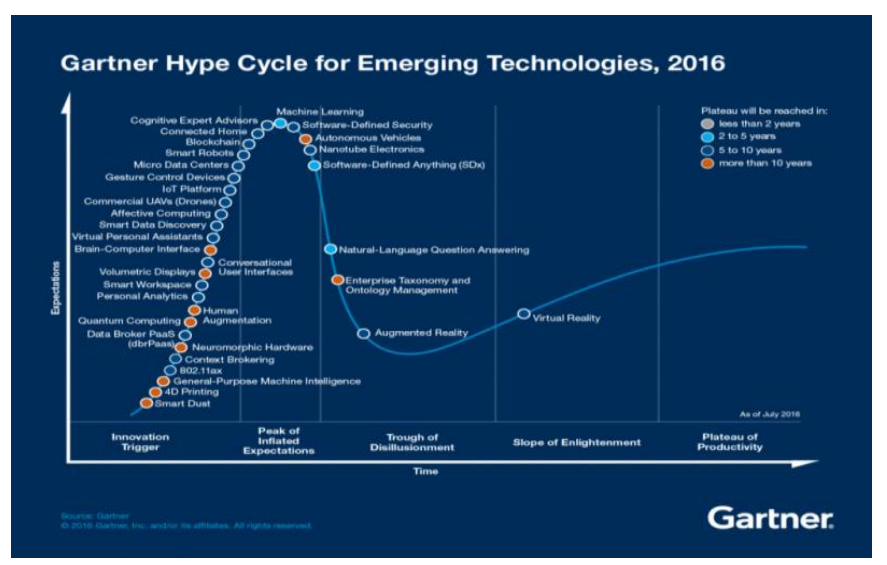

In this work, analysts Avivah Litan, Adrian Leow et al.(2019) summarise that Blockchain technology is sliding into the Trough of Disillusionment in Gartner's Hype Cycle. Despite this, CIOs must prepare for the "blockchain spring" that will emerge once the core-enabling technologies and use cases evolve and mature, resulting in significant benefits for the enterprise.

\section{How it works?}

The blockchain is basically a distributed database. Think of a giant, global spreadsheet that runs on millions and millions of computers. It's distributed. It's open source, so anyone can change the underlying code, and they can see what's going on. It's truly peer to peer; it doesn't require powerful intermediaries to authenticate or to settle transactions.

\section{WHAT BLOCKCHAIN CAN SOLVE}

The big question is, is blockchain the future? When pondering its place in society, MIT's Technology Review estimated that in 2019, blockchain will play a role in $21 \%$ of global economic affairs. With this in mind, here are a few of the economic problems that blockchain could solve, now and in the future.

\section{1) Global trade and regulation}

Globalisation is the effect that technology has had worldwide - making financial services easier, convenient, and affordable. A Cross-border transaction fee is an issue that could divide a country's population into those who can afford financial services and those who can't. In Africa alone, with 54 countries and different currencies, exchange rates and legalities, this provides a challenge for such transactions.

\section{2) Property rights and real estate}

Transparency and accountability are the two big issues at play in this sector. Records of who owns land or property are usually kept by the government - but what if this is lost, or stolen, or someone can't prove ownership? In this way, blockchain, due to its natural characteristics, is a useful tool to determine ownership. Blockchain can replace the middleman without incurring further fees, and aid in verifying the data.

\section{3) Proof of identity}

Refugees often flee without having formal identification on their person. This causes innumerable delays in providing verifiable proof of their identities in order to obtain legal documents. "An identity is essential for nearly everything needed in a crisis - securing shelter, accessing services, crossing borders, and receiving funds. These are challenging enough when you're distressed by displacement; they're exponentially so when you don't have an identity." It's estimated that there are at least 1 billion people globally, who don't have a valid identity document.

\section{A. So how can Blockchain Technology Change our life?}

The social impact of blockchain technology has already begun to be realized and this may just be the tip of the iceberg. Cryptocurrencies have already provided doubts over financial services through digital wallets, the rollout of ATMs and the provision of loans and payment systems. When considering the fact that there are more than 2 billion people in the world today without a bank account, such shift is certainly a life changer and can only be a positive one. Perhaps the shift for cryptocurrencies will be easier for developing countries than the process of fiat money and credit cards. In a way, it is similar to the transformation that developing countries had with cellular phones. It was easier to acquire mass amounts of cell phones than to provide a new infrastructure for landlines phones.

Decentralizing away from governments and the control over people's lives will likely be embraced by many and the social implications can be quite significant. One only needs to consider the spate of identity thefts that have hit the news in 


\section{International Journal of Engineering Applied Sciences and Technology, 2020 \\ Vol. 4, Issue 9, ISSN No. 2455-2143, Pages 149-152 \\ Published Online January 2020 in IJEAST (http://www.ijeast.com)}

recent years. Handing the control of identification to the people would certainly eliminate such events and allow people to reveal information with trust.

Perhaps the greatest social impact of blockchain technology is here.

\section{B. Banks are Scared of Blockchain!}

Cost savings within the banking industry have been estimated to range from $\$ 16$ bn to $\$ 20$ bn per year through the adoption of blockchain technology.

It's not just the cost savings, however. Consider a shift in fundraising approaches away from the debt capital markets and initial public offerings to Initial Coin Offerings (ICO). If we take it a step further, would there be any need for the equity markets as we know them today? Cryptocurrencies could replace traditional shares of companies, listed or unlisted and the blockchain technology would then manage and record the transfer of shares for the given company on a decentralized ledger. Maybe it will not happen tomorrow, but, it could be the reality.

What would be the purpose of central banks when the use of paper money slumps in favour of virtual money? Japan has already embraced Cryptocurrencies as legal tender. As the market continues to evolve, others will follow. If central bankers want to continue enjoying their days in the limelight, they're going to need to catch up. One function that remains lacking is the regulatory side. Taking the control away from the governments, perhaps central banks will eventually become equivalent to oversight committees. Drawing up the regulatory framework and mapping out the progressive inclusion of blockchain technology into the financial system. Some would argue that such a function would be of far greater value. For now, the world's largest banks and central banks have begun to invest significant capital into the use of blockchain technology. While bank CEO's have been generally dismissive towards Bitcoin, the view is quite different when it comes to the underlying technology.

\section{Blockchain is not only Bitcoin, it's much more than that}

Having discussed the positive impact that blockchain technology can have on democracy, there are countless other areas in which blockchain technology can have a dramatic effect. Some examples include:

Supply Chains: The ability to track foods from farm to shelf is one that has recently made the news. IBM announced that it has begun working with the larger food suppliers, including Nestle and Walmart, to take advantage of blockchain technology. Of particular interest to food, suppliers are being able to identify the source of food contamination, as well as being able to track the producer within the food supply chain. Beyond food, the transparency of blockchain can also give consumers the true source of manufactured goods, which has become important in today's society.

Energy sector: The trading of energy with the use of blockchain could allow the consumer to sell excess energy to their neighbours, removing the control from the utility companies. Similar to financial markets, there may even be a range of prices as supply and demand dictate price.

Governments: Governments have already begun pilot projects to incorporate blockchain technology into their daily operations. The intention being to make the efficiency gains that the technology can deliver. In the UK, the government has used blockchain technology in the disbursement of student loans and also to track the payment of benefits to the underprivileged. The government's view is that blockchain could reduce corruption, the number of fraud cases and costs by shifting away from the current use of paper.

Healthcare: The removal of the paper trail in the healthcare system and making patients' medical records are available to the patients' without the threat of hacking or leaking. Additionally, a decentralized ledger of medical data may even be able to provide the necessary data points to support the fight against virus and disease.

Music Industry: Protection of rights and distribution of earnings within the music industry is a key consideration, as the industry looks at ways to adopt the technology. Removing the ability for piracy and allowing listeners to download music stored on the blockchain, paying for the music with cryptocurrency would be one of the paradigm shifts in the industry. It would also mean that the right people get paid... It may well be the death of distributors, but it's unlikely that artists within the industry will lose any sleep over such a prospect.

These are just a small number of examples. Blockchain technology is being explored across all of the major sectors and with many industries already rolling out pilot projects, the skeptics may have to eat their words.

\section{CONCLUSION}

Blockchain is the kind of technological breakthrough that has the potential to make global changes of historic proportions. Its predicted impact on the world economy is big enough that some of the biggest companies are already preparing for it.

\section{REFERENCE}

[1] Nakamoto, S.,(2008) Bitcoin: A peer-to-peer electronic cash system, http://www.bitcoin.org

[2] Nesbitt Audrey (2018) Choosing the Right Blockchain Platform for Your Startup, 
https://medium.com/swlh/choosing-the-right-blockchainplatform-for-your-startup-1d0554277a4b

[3] Kosba A., Miller A., Shi E., Wen Z., and Papamanthou C.,(2016) "Hawk: The blockchain model of cryptography and privacy-preserving smart contracts," in Proceedings of IEEE Symposium on Security and Privacy (SP), San Jose, CA, USA, 2016, pp. 839-858.

[4] Foroglou G. and Tsilidou A.-L.,(2015) "Further applications of the blockchain," 2015

[5] NRI, "Survey on blockchain technologies and related services," Tech. Rep., 2015. [Online]. Available: http://www.meti.go.jp/english/press/ 2016/pdf/0531 01f.pdf

[6] Buterin V.,(2014) "A next-generation smart contract and decentralized application platform," white paper, 2014.

[7] Bonneau J., Narayanan A., Miller A., Clark J., Kroll J. A., and Felten E. W.,(2014) "Mixcoin: Anonymity for bitcoin with accountable mixes," in Proceedings of International Conference on Financial Cryptography and Data Security, Berlin, Heidelberg, 2014, pp. 486-504.

[8] Body, A. (2018). Blockchain: how to choose the right tech for your business. Online at https://medium.com/@abody/blockchain-how-to-choosethe-right-tech-for-your-business-aa4597d7ee7c.

[9] Casey, M.J. and P. Vigna (2018b), The Trust Machine: The Blockchain and the Future of Everything, St. Martin's Press.

[10] Joshi, P. (2017). "How Blockchain Can Revolutionise the Music and Media Industries." https://yourstory.com/2017/10/how-blockchain-canrevolutionise-the-music-and-media-industries/.

[11] Desai, V. (2017). "Counting the Uncounted: 1.1 Billion People Without IDs." June 6. https://blogs. worldbank.org/ic4d/counting-invisible-11-billion-peoplewithout-proof-legal-id.

[12] Bajpai, P. (2016). "Blockchain Technology Can Help Reduce the Flow of Counterfeit Drugs." December 14. http://www.nasdaq.com/article/blockchain-technologycan-help-reduce-flow-of-counterfeitdrugs-cm721230.

[13] Dhillon, V., Metcalf, D., \& Hooper, M. (2017). Blockchain Enabled Applications: Understand the Blockchain Ecosystem and How to Make it Work for You. Apress.

[14] Ben-Sasson E., Chiesa A., Garman C., Green M., Miers I., Tromer E., Virza M.,(2014) "Zerocash: Decentralized anonymous payments from Bitcoin", S\&P, 2014.

[15] Bonneau J., Narayanan A., Miller A., Clark J., Kroll J. A., and Felten E. W.,(2015), "Research Perspectives and Challenges for Bitcoin and Cryptocurrencies", S\&P, 2015.
[16] Barber S., Boyen X., Shi E., Uzun E.,(2012) "Bitter to Better-How to Make Bitcoin a Better Currency", Financial Cryptography, 2012.

[17] Pass R., Shelat Abhi,(2015) "Micropayments for peer-topeer currencies", CCS, 2015.

[18] Andrychowicz M., Dziembowski S., Malinowski D., Mazurek L.(2015), "On the Malleability of Bitcoin Transactions", Workshop on Bitcoin Research, 2015.

[19] Haber Stuart, Stornetta W.Scott, (1991) How to timestamp a digital document Journal of Cryptology, https://doi.org/cwwxd4 DOI: 10.1007/bf00196791

[20] Bayer Dave, Haber Stuart, Stornetta W. Scott,(1993) Improving the Efficiency and Reliability of Digital TimeStamping Sequences II (1993) https://doi.org/bn4rpx DOI: $10.1007 / 978-1-4613-9323-8 \_24$

[21] https://www.gartner.com/en/documents/3947355/hypecycle-for-blockchain-technologies-2019 